\title{
Hepatocellular carcinoma in hereditary hemochromatosis
}

\author{
PAUL C ADAMS, MD
}

PC ADAMS. Hepatocellular carcinoma in hereditary hemochromatosis. Can J Gastroenterol 1993;7(1):37-41. The prevalence of hepatocellular carcinoma was studied retrospectively in 93 hemochromatosis patients over a mean followup period of 7.7 years (range zero to 33 ). The presence of clinically evident hepatocellular carcinoma was established by tissue diagnosis in all patients and was not sought by screening for disease. Hepatocellular carcinoma was diagnosed in seven of 93 patients $(7.5 \%)$. All patients with hepatocellular carcinoma had cirrhosis. Other neoplasms were found in five patients (one bile duct, two breast, one pancreas and one brain). The mortality ratio (observed casestexpected cases) for hepatocellular carcinoma was 350 . The prevalence of hepatocellular carcinoma in hemochromatosis patients was also reviewed in 962 hemochromatosis patients from 11 previous studies.

Key Words: Cancer, Hepatocellular carcinoma, Hepatoma, Iron

\section{Cancer hépatocellulaire dans l'hémochromatose héréditaire}

RÉSUMÉ: La prévalence du cancer hépatocellulaire a été étudiée rétrospectivement chez 93 patients atteints d'hémochromatose sur une période moyenne de suivi de 7,7 ans (entre 0 et 33 ans). La présence d'un cancer hépatocellulaire clinique a été confirmée par un diagnostic au niveau des tissus chez tous les patients sans avoir par ailleurs fait l'objet d'un dépistage systématique de la maladie. Le cancer hépatocellulaire a été diagnostiqué chez sept patients sur 93 $(7,5 \%)$. Tous les patients atteints de cancer hépatocellulaire présentaient une cirrhose. D'autres néoplasies ont été notées chez cinq patients (une des voies biliaires, deux du sein, une du pancréas et un du cerveau). Le ratio de mortalité (cas observés:cas prévus) pour le cancer hépatocellulaire était de 350. La prévalence du cancer hépatocellulaire chez les patients atteints d'hémochromatose a également été passée en revue chez 962 patients atteints d'hémochromatose présentés dans 11 études précédentes.

Department of Medicine, University of Western Ontario, London, Ontario

Correspondence: Dr Paul C Adams, Department of Medicine, University Hospital, PO Box 5339, 339 Windermere Road, London, Ontario, N6A 5A5. Telephone (519) 663-3513

Received for publication June 18, 1992. Accepted October 8, 1992
$\mathrm{H}$ EMOCHROMATOSIS IS A COMMON genetic disease with a prevalence of approximately one in 300 in the Caucasian population (1). The disease has an autosomal recessive inheritance pattern and results in the pathological accumulation of iron in the liver, pancreas, heart and other organs, eventually leading to cirrhosis of the liver. Hepatocellular carcinoma has been reported as a complication of cirrhosis in many series of hemochromatosis patients (2-17). In this study, the prevalence of hepatocellular carcinoma was studied in 93 hemochromatosis patients (mean follow up 7.7 years, range zero to 33 ).

\section{PATIENTS AND METHODS}

The diagnosis of hemochromatosis was suspected clinically in the proband case by an elevation in serum ferritin and transferrin saturation, and confirmed by the presence of parenchymal iron overload on percutaneous liver biopsy with determination of hepatic iron concentration. Family members, particularly siblings, were investigated with a serum ferritin, transferrin saturation, human lymphocyte antigens (HLA) - A and B typing, and liver biopsy was performed in putative homo- 


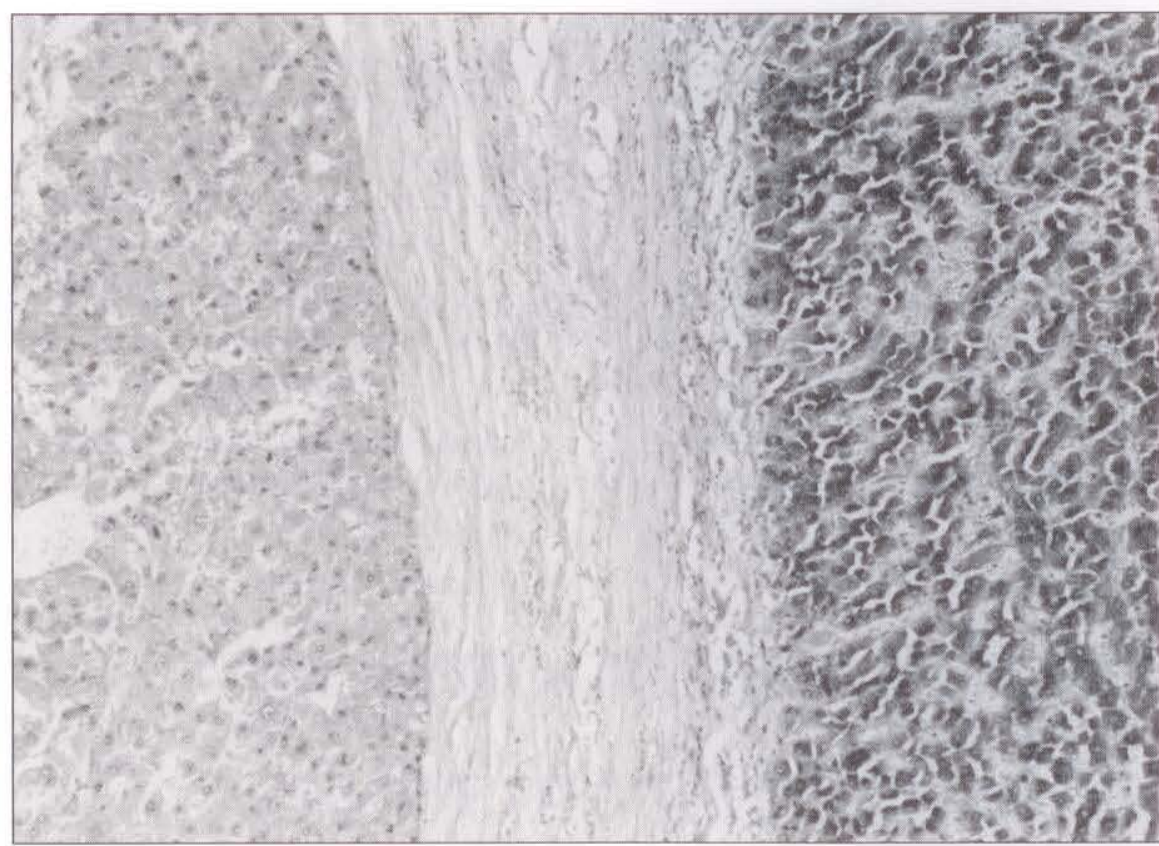

Figure 1) Photomicrograph of a hepatocellular carcinoma in an iron-loaded hemochromatosis patient. The tumour (left) shows much less stainable iron than the cirrhotic hepatic parenchyma (right). Magnification $\times 200$. Hematoxylin, phloxin, saffron and Prussian blue stain zygotes. The clinical profile, iron parameters, survival data and causes of death of some of these patients have been previously described $(2,14,18$ 20). Patients with other conditions associated with iron overload, such as iron-loading anemias, multiple transfusions and porphyria cutanea tarda, were excluded. Patients with a significant history of daily alcohol consumption were only included if the diagnosis of iron overload was confirmed in an HLA-identical sibling without a history of alcohol use. Iron- loaded patients were treated with weekly venesections of approximately $500 \mathrm{~mL}$ blood until serum ferritin was approximately $50 \mu \mathrm{g} / \mathrm{L}$, followed with serum ferritin annually and retreatment if iron stores reaccumulated as previously described $(2,19)$. Patients were not routinely screened for hepatocellular carcinoma but underwent history and physical examinations at the annual review.

The author's hospital is a national referral centre for hemochromatosis, although no patients were referred with a known diagnosis of hepatocellular carcinoma. A deteriorating condition (ascites, jaundice, bleeding) was the most common reason for further investigations - including abdominal paracentesis, serum alpha-fetoprotein, abdominal ultrasound, computed tomography (CT) scan and guided liver biopsy leading to a diagnosis of hepatocellular carcinoma. Hepatocellular carcinoma was confirmed by one pathologist (all tumours had the characteristic trabecular pattern and bile present within

\section{TABLE 1}

Hemochromatosis patients with hepatocellular carcinoma

\begin{tabular}{lccccc}
\hline $\begin{array}{l}\text { Age } \\
\text { (years) }\end{array}$ & $\begin{array}{c}\alpha \text {-fetoprotein } \\
(0 \text { to 12) }\end{array}$ & $\begin{array}{c}\text { Iron status } \\
\text { symptoms }\end{array}$ & $\begin{array}{c}\text { Tumour size } \\
\text { sym) }\end{array}$ & $\begin{array}{c}\text { Survival } \\
\text { (months) }\end{array}$ \\
\hline 55 & 3733 & Depleted & Incidental & Multinodular & 0.5 \\
68 & not done & Loaded & Jaundice & 4.4 & 12 \\
71 & not done & Depleted & Ascites & Diffuse & 1 \\
46 & 19,454 & Depleted & Jaundice & Diffuse & 3 \\
71 & 5800 & Loaded & Ascites & 10 & 1 \\
67 & 4 & Depleted & Ascites & 15 & 2 \\
70 & 6914 & Depleted & Variceal bleeding & 12 & 12 \\
\hline
\end{tabular}

tumour cells). All patients with hepatocellular carcinoma were negative for the hepatitis B surface antigen. Patients and liver tissue were not routinely tested for the presence of viral markers to hepatitis $\mathrm{C}$ or $\mathrm{B}$, or hepatitis $\mathrm{B}$ virus DNA.

The expected incidence of hepatocellular carcinoma was estimated from Canadian age/sex specific death rates from hepatocellular carcinoma in 10 . year age intervals (21). Observed cases were treated as a Poisson variable and the $95 \%$ confidence intervals were calculated as previously described (22). Mortality ratios were expressed as the observed/expected cases of carcinoma.

\section{RESULTS}

Patients were followed for a mean of 7.7 years (range zero to 33 ). Of the 93 patients ( 59 male, 34 female), there were 54 proband cases and 39 patients discovered through family screening. There were 30 patients with cirrhosis present at initial diagnosis. All patients with hepatocellular carcinoma had cirrhosis and the disease was fatal in all cases. The tumour occurred in five of seven patients after iron depletion by venesection therapy. All tumours were confirmed histologically either by percutaneous biopsy or at autopsy. There were no tumours that were considered eligible for resection or transplantation. A characteristic tumour in an iron-loaded hemochromatosis patient is shown in Figure 1. The clinical features of patients with hepatocellular carcinoma are shown in Table 1.

The expected number of cases from hepatocellular carcinoma in an age/sex matched population over the mean fol. low-up period in this study was 0.02 , but seven patients were observed. Therefore, patients with hemochromatosis had an observed to expected ratio (mortality ratio) of 350 for hepatocellular carcinoma. The number of observed cases of hepatocellular carcinoma was considered to be significantly increased because the expected number of cases was outside the $95 \%$ confidence intervals for the observed num. ber of deaths (7). A summary of this study, nine other follow-up series and two autopsy series of hemochromatosis 
patients is shown in Figures 2 and 3. Patients reported with carcinoma from other extrahepatic sites are shown in Figure 4.

\section{DISCUSSION}

Hepatocellular carcinoma in hemochromatosis: In this retrospective study of the long term follow-up of patients with hemochromatosis, a diagnosis of hepatocellular carcinoma was established in seven of 93 patients $(7.5 \%)$; it is possible that this is an underestimate of the true prevalence of hepatocellular carcinoma since small tumours may have been detected in other hemochromatosis patients at autopsy with meticulous sectioning of cirrhotic livers. Because the author's centre is a referral centre for patients with hemochromatosis, a referral bias cannot be excluded in this retrospective study. However the close correlation between the prevalence of carcinoma in autopsy studies and follow-up studies suggests that unlike with alcoholic cirrhosis, hepatocellular carcinoma is the direct cause of death in hemochromatosis patients. The elucidation of hemochromatosis genetics has led to the earlier diagnosis in family members in the precirrhotic stage of disease in more recent studies $(7,14,23)$. Patients that undergo iron depletion therapy by venesection before the development of cirrhosis have a survival comparable to the general population $(2,7)$. In the present study, less than one-third of the patients had cirrhosis at diagnosis and, therefore, the population was at a lower risk of developing hepatocellular car-' cinoma than a cohort of predominantly cirrhotic patients. In the combined series of 859 hemochromatosis patients in follow-up studies, the prevalence of hepatocellular carcinoma was 92 of 859 $(10.7 \%)$ (Figure 2$)$. If only cirrhotic patients were considered (including two autopsy series), the prevalence of hepatocelluar carcinoma was 120 of $649(18.5 \%)$ (Figure 3$)$.

Hepatocellular carcinoma in cirrhosis of any cause: Many authors have noted that the risk of hepatocellular carcinoma seems to be high, particularly in cirrhosis associated with hemochromatosis compared with other types of cir-

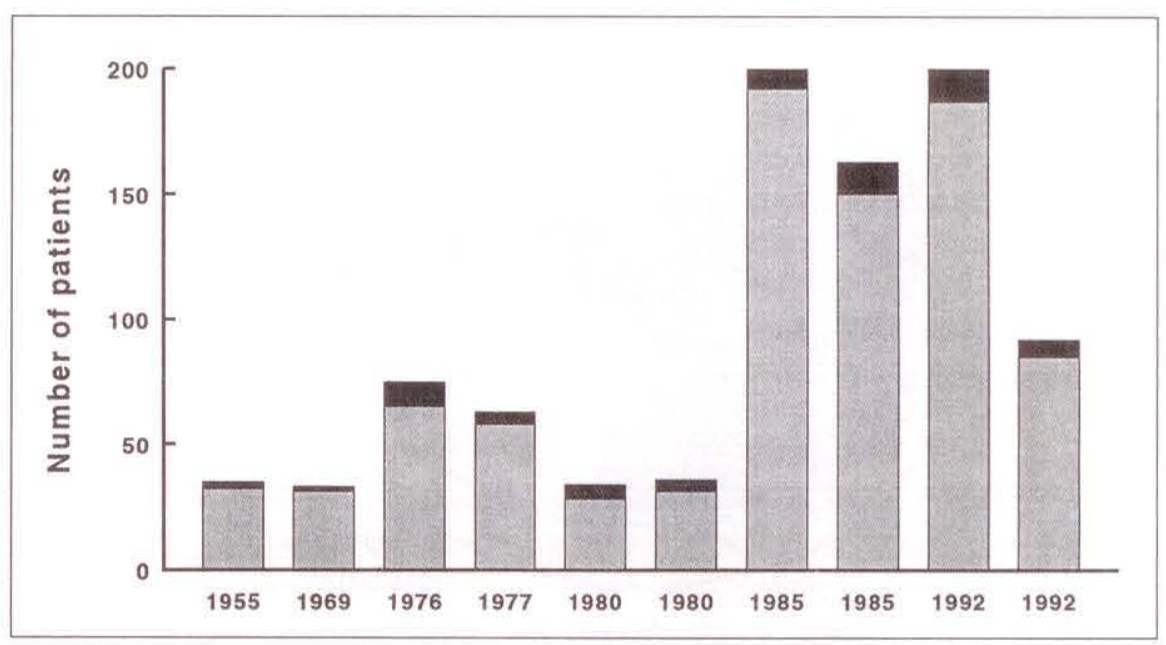

Figure 2) Prevalence of hepatocellular carcinoma in this and nine previous studies (references $3-7,10,15-17)$ of hemochromatosis patients. The black bar represents the number of patients with hepatocellular carcinoma as a proportion of the total number of patients studied. There were 92 of 859 patients $(10.7 \%)$ with hepatocellular carcinoma in these series

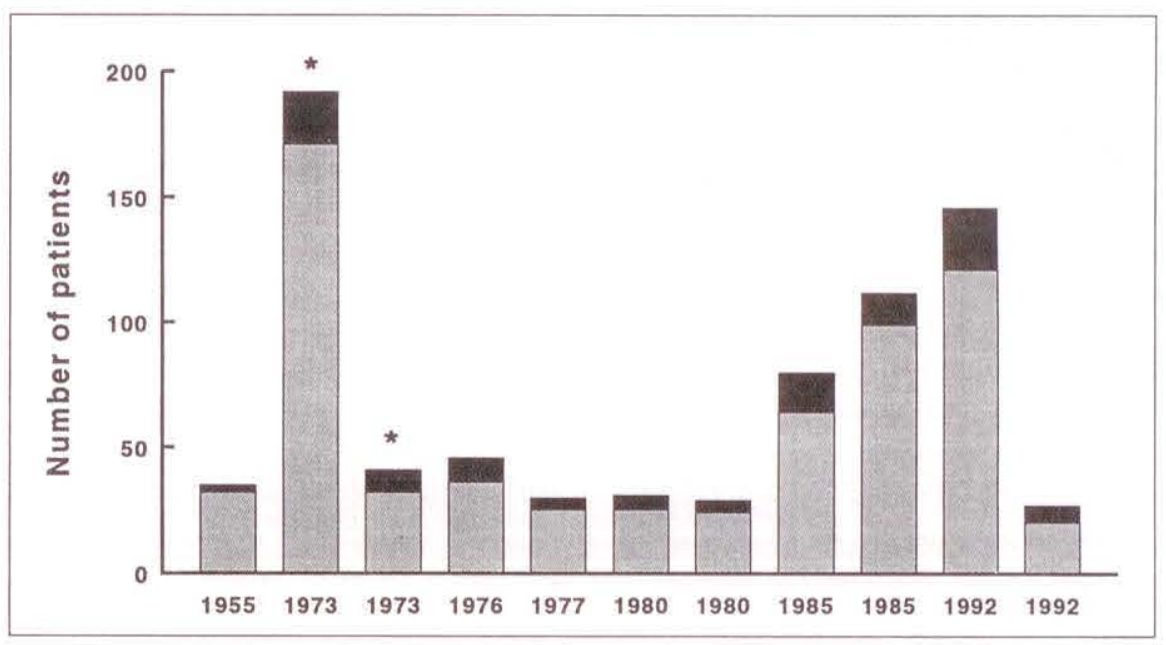

Figure 3) Prevalence of hepatocellular carcinoma in this and 11 previous studies (references $3-7,10,12-14,16,17)$ in hemochromatosis patients with cirrhosis. The black bar represents the number of patients with hepatocellular carcinoma as a proportion of the total number of patients studied. There were 120 of 649 (18.5\%) patients with hepatocellular carcinoma in these series. *An autopsy study rather than a follow-up study

rhosis. An unresolved question is whether this is a unique feature of the natural history of this disease, or if the more favorable prognosis compared with other cirrhotic patients (7) allows for more time to develop a hepatocellular carcinoma. Purtilo et al (12) reported hepatocellular carcinoma in autopsies in 21 of $192(10.9 \%)$ of hemochromatosis patients and in 51 of $312(16.3 \%)$ of patients with post necrotic cirrhosis. MacSween (13) described hepatocellular carcinoma in autopsies in nine of 41 (22\%) hemochromatosis patients and in 44 of 322
(13.7\%) patients with cryptogenic cirrhosis. Tanaka et al (24) followed 582 cirrhotic patients (hepatitis B, cryptogenic, alcoholic) for up to 26 years and detected hepatocellular carcinoma in $44 \%$. The prevalence of hepatocellular carcinoma in hepatitis $\mathrm{C}$-associated cirrhosis was reported to be 20 of 201 $(10 \%)$ in a study of 447 patients from Italy followed for a mean follow-up period of 33 months (25). Other studies have suggested that there is a significant association between hepatitis C-related cirrhosis and the development of hepatocellular carcinoma. Hepatitis C may 


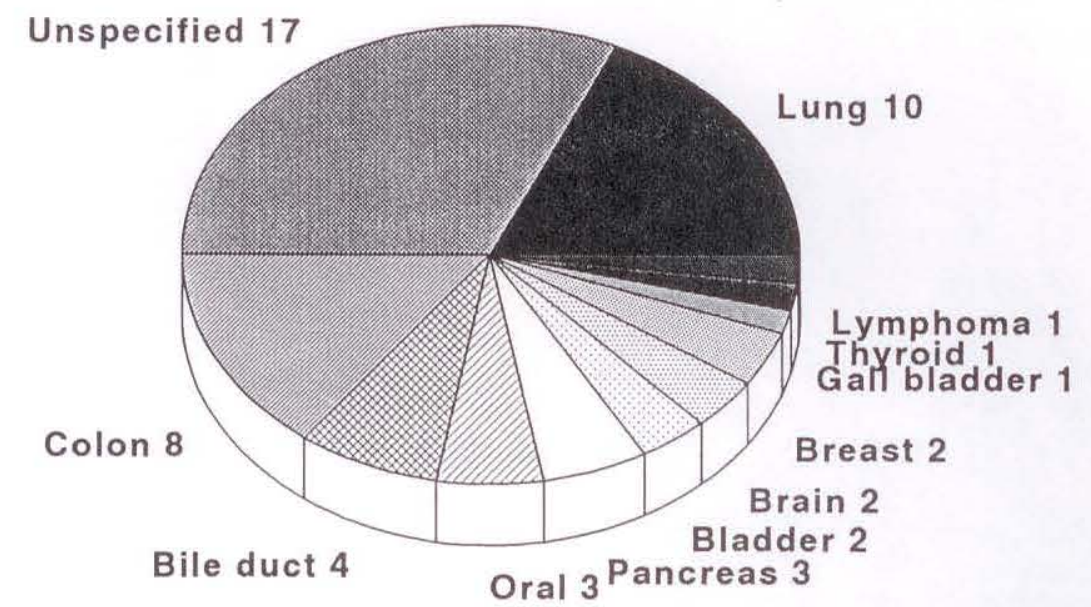

Figure 4) The number of cases and site of origin of extrahepatic carcinoma in this study and nine previous follow-up series (references 3-7, 10,15-17) involving 859 patients with hemochromatosis

eventually prove to be a more significant risk factor than that established for hepatitis B (26). The detection of viral markers for hepatitis $B$ and $C$ in hemochromatosis patients with hepatocellular carcinoma raises the important question of co-factors in the development of the carcinoma (27). In fact, in the 25 hemochromatosis patients reported by Fargion et al (17), $40 \%$ had evidence of hepatitis C.

Recent studies (28) have suggested the role of a mutation in the $\mathrm{p} 53$ gene in hepatocellular carcinoma. The proposed mechanism of carcinogenesis in cirrhosis is that a regenerative hyperplastic response may develop into a hepatocellular carcinoma (26). The late development of the tumour many years after the iron has been removed in hemochromatosis or many years after an alcoholic has abstained is consistent with this hypothesis. Although hemochromatosis patients have a significantly increased risk of hepatocellular carcinoma, it seems comparable in many other studies of nonalcoholic cirrhosis. Hepatocellular carcinoma is not a feature of other noncirrhotic diseases associated with iron overload, such as thalassemia and sideroblastic anemia, suggesting that the cirrhosis - rather than iron - is the major risk factor.

Screening for hepatocellular carcinoma: Since hepatocellular carcinoma is a known and dreaded complication of hemochromatosis, is there any proven value in screening hemochromatosis patients with cirrhosis for the tumour? Sensitive assays for alpha-fetoprotein and real-time ultrasonography have been studied as screening tools in hemochromatosis and other types of cirrhosis (10,29-33). Chayvialle et al (10) followed 77 hemochromatosis patients at three-month intervals with alpha-fetoprotein and ultrasound examination, and found five patients with hepatocellular carcinoma, but no effective therapy was available. The experience of screening hepatitis B patients has also been disappointing primarily because once discovered, resection usually is not feasible and transplantation for hepatocellular carcinoma has a high incidence of recurrent carcinoma $(1,33)$. The fact that the hepatocellular carcinoma in hemochromatosis does not contain excess iron raises the possibility of assessing neoplastic or preneoplastic lesions in the liver by using the known differential densities of normal and iron-loaded tissue on dual image CT scanning and magnetic resonance imaging (34). The presence of iron-free foci on liver biopsy has been described in $7.4 \%$ of hemochromatosis patients; these patients may have a greater risk of malignant transformation (35), but many patients (as in the present study) develop carcinoma with normal iron stores in the liver. Prevalence of extrahepatic carcinoma in hemochromatosis: Several authors
$(5,6)$ have suggested that hemochromatosis patients may have an increased risk of extrahepatic carcinoma possibly because of the direct effect of iron as a carcinogen. Bradbear et al (3) concluded in a cohort study of 208 hemochromatosis patients that there was no statistically significant increased prevalence of extrahepatic carcinoma in hemochromatosis. An increased prevalence of extrahepatic carcinoma was suggested by Bomford et al (6) who described 10 extrahepatic tumours in 45 hemochromatosis patients (22\%) and Amman et al (5) who described six tumours in 36 cases (17\%). The prevalence of extrahepatic carcinoma in hemochromatosis in the pooled series of patients is shown in Figure 4. The lack of specific information about age, control populations and regional differences in the prevalence of sitespecific carcinoma has limited the ability to pool the data in this group of patients.

Iron as a carcinogen in the general population: Population studies have suggested that the prevalence of carcinoma of any site increases in patients with increased body iron stores as assessed by serum ferritin and transferrin saturation (36-38). Patients with cancer of the esophagus, colon, lung and bladder have a higher transferrin saturation than similar patients without cancer $(36,37)$. The hypothesis that iron enhances cancer cell growth has been studied in experimental animals $(39,40)$ and suggests that iron is an essential nutrient to rapidly growing neoplastic cells. Iron overload often is associated with immunosuppression which may predispose to the development of carcinoma. It is these same factors that contribute to the increased risk of infection in patients with iron overload (41). Chromosomal damage has also been described in lymphocytes from patients with hemochromatosis (42). Furthermore, hepatocellular carcinoma often occurs after venesection therapy has removed excess iron from the body.

\section{CONCLUSIONS}

In summary, hemochromatosis has a high prevalence of hepatocellular carcinoma as do many other causes of cir- 
rhosis. The presence of cirrhosis most likely is the major risk factor, although the presence of excess iron or viral infections as co-factors in the development of hepatocellular carcinoma requires further study. Extrahepatic carcinoma occurs frequently in hemochromatosis, with lung and colon carcinoma being the most common extrahepatic sites. Early diagnosis and treatment of hemochromatosis before the development of cirrhosis is the most effective method to prevent hepatocellular carcinoma.

ACKNOWLEDGEMENTS: The author acknowledges the advice and assistance of Drs LS Valberg, JV Frei, C Ghent, M Sherman and M Speechley. The author is a Career Scientist of the Ministry of Health of Ontario

\section{REFERENCES}

1. Adams PC, Halliday JW, Powell LW.

Early diagnosis and treatment of hemochromatosis. Adv Int Med 1989;34:111-26.

2. Adams PC, Speechley M, Kertesz AE. Long term survival analysis in hereditary hemochromatosis. Gastroenterology 1991;101:368-72.

3. Bradbear RA, Bain C, Siskind V, et al. Cohort study of internal malignancy in genetic hemochromatosis and other chronic nonalcoholic liver diseases. JNCI 1985;75:81-4.

4. Milder MS, Cook JD, Stray S, et al. Idiopathic hemochromatosis, an interim report. Medicine 1980;159:34-49.

5. Amman RW, Muller E, Bansky J, et al. High incidence of extrahepatic carcinomas in idiopathic hemochromatosis. Scand J Gastroenterol 1980;15:733-6.

6. Bomford A, Williams R. Long term results of venesection therapy in idiopathic haemochromatosis. Quart J Med 1976;180:611-23.

7. Niederau C, Fischer R, Sonnenberg A, et al. Survival and causes of death in cirrhotic and noncirrhotic patients with primary hemochromatosis. N Engl J Med 1985;1313:1256-62.

8. Strohmeyer G, Niederau C, Stremmel W. Survival and causes of death in hemochromatosis. Ann NY Acad Sci 1988;526:245-57.

9. Tiniakos G, Williams R. Cirrhotic process, liver cell carcinoma and extrahepatic tumors in idiopathic hemochromatosis. Appl Pathol 1988;6:128-38.

10. Chayvialle J, Brissot P, Pelletier M], et al. Alpha-fetoprotein screening in patients with idiopathic

hemochromatosis and liver cirrhosis.

Digestion 1977;16:118-27.

11. Parker R. The incidence of primary hepatic carcinoma in cirrhosis. Proc R Soc Med 1957;50:145-52.

12. Purtilo D, Gottlieb L. Cirrhosis and hepatoma occuring at the Boston City Hospital (1917-1968). Cancer 1973;32:458-62.

13. MacSween R, Scott AR. Hepatic cirrhosis: A clinicopathological review of 520 cases. J Clin Pathol 1973;26:936-42.

14. Adams PC, Kertesz AE, Valberg LS. Clinical presentation of hemochromatosis: A changing scene. Am J Med 1991;90:445-9.

15. Whitcomb F, Lummis FR, Mejia JA, et al. ldiopathic hemochromatosis: Clinical and laboratory features in 33 patients. Lahey Clin Found Bull 1969;18:109-16.

16. Kleckner MS, Kark RM, Baker LA, et al. Clinical features, pathology and therapy of hemochromatosis. JAMA 1955;117:1471-6.

17. Fargion S, Mandelli C, Piperno A, et al. Survival and prognostic factors in 212 Italian patients with genetic hemochromatosis. Hepatology 1992;15:655-9.

18. Adams PC. Hepatic iron in hemochromatosis. Dig Dis Sci 1990;35:690-2.

19. Adams PC, Kertesz AE, Valberg LS. Rate of iron reaccumulation after iron depletion therapy in hemochromatosis J Clin Gastroenterol. (In press)

20. Lin E, Adams PC. Biochemical liver profile in hemochromatosis. A survey of 100 patients. J Clin Gastroenterol 1991;13:316-20.

21. Kurihara M, Aoki M, Hisamichi S. Cancer mortality statistics in the world. Nagoya, Japan: The University of Nagoya Press, 1984;98-9.

22. Singer RB, Levinson L, eds. Medical Risks: Patterns of Mortality and Survival. Lexington: DC Heath, 1976;129-31.

23. Edwards CQ, Cartwright GE, Skolnick $\mathrm{MH}$, et al. Homozygosity for hemochromatosis; clinical manifestations. Ann Intern Med 1980;93:519-25.

24. Tanaka R, Itoshima $T$, Nagashima $H$ Follow up study of 582 liver cirrhosis patients for 26 years in Japan. Liver 1987; 17:316-29.

25. Colombo M, DeFranchis R, Del Ninno E, et al. Hepatocellular carcinoma in Italian patients with cirrhosis. $\mathrm{N}$ Engl ] Med 1991;325:675-80.

26. Wands JR, Blum HE. Primary hepatocellular carcinoma. N Engl J Med 1991;325:729-31.

27. Deugnier $Y$, Battistelli D, Jouanolle $H$, et al. Serum HBV markers in genetic hemochromatosis: A study of 272 homozygous patients. J Hepatol 1991;13:286-90.

28. Hsu IC, Metcalf RA, Sun T, et al. Mutational hotspot in the p 53 gene in human hepatocellular carcinoma. Nature 1991;350:427-8.

29. Okuda K. Primary liver cancer. Dig Dis Sci 1986;31:133S-46S.

30. Regan LS. Screening for hepatocellular carcinoma in high risk individuals. A clinical review. Arch lnt Med 1989;149:1741-4.

31. Lee HS, Chung YH, Kim CY. Specificities of serum alpha-fetoprotein in $\mathrm{HBs} \mathrm{Ag}+$ and $\mathrm{HBs} \mathrm{Ag}$ - patients in the diagnosis of hepatocellular carcinoma. Hepatology 1991;14:68-72.

32. DiBiseglie AM. Hepatocellular carcinoma. Ann Intern Med 1988;108:390-401.

33. Okuda K. Early recognition of hepatocellular carcinoma. Hepatology 1986;4:729-38.

34. Bonkovsky H, Slaker DP, Billes E, et al. Usefulness and limitations of laboratory and hepatic imaging studies in iron storage disease.

Gastroenterology 1990;99:1079-91.

35. Deugnier Y, Olivier L, Bruno T, et al. Liver pathology in genetic hemochromatosis: A review of 135 homozygous cases and their bioclinical correlations. Gastroenterology 1992;102:2050-9.

36. Stevens RG, Beasley RP, Blumberg BS. Iron binding proteins and risk of cancer in Taiwan. J Natl Cancer Instit 1986;76:605-10.

37. Stevens RG, Jones DY, Micozzi MS, et al. Body iron stores and risk of cancer. N Engl J Med 1988;319:1047-52.

38. Selby JV, Friedman GD. Epidemiologic evidence of an association between body iron stores and risk of cancer. Int J Canc 1988;41:677-82.

39. Smith AG, Francis JE, Carthew P. Iron as a synergist for hepatocellular carcinoma induced by bichlorinated biphenyls in $\mathrm{Ah}$ responsive $\mathrm{C} 57 \mathrm{BL} /$ $10 \mathrm{ScSn}$ mice. Carcinogenesis 1990;11:437-44.

40. Thompson HJ, Kennedy K, Witt M, et al. Effect of dietary iron in excess on the induction of mammary carcinogenesis by 1-methyl-1nitrosurea. Carcinogenesis 1991;12:111-4.

41. Weinberg ED. Iron withholding: A defense against infection and neoplasia. Physiol Rev 1984;164:65-102.

42. Nordenson I, Ritter B, Beckman A, Beckman L. Idiopathic hemochromatosis and chromosomal damage. Human Hered 1992;42:143-5. 


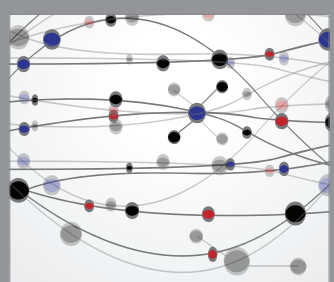

The Scientific World Journal
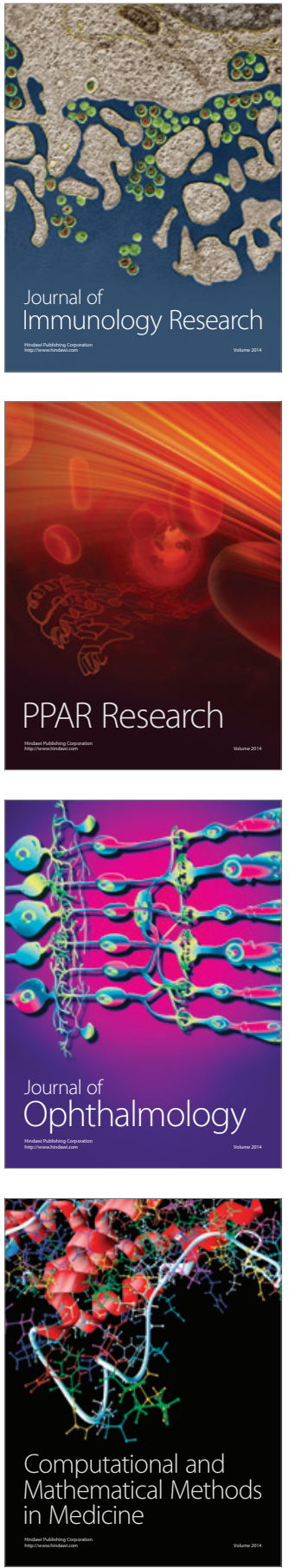

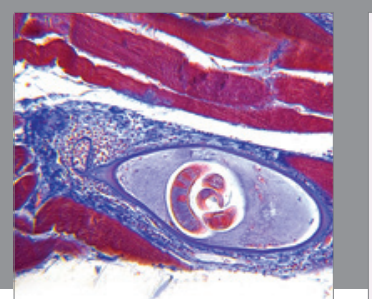

Gastroenterology Research and Practice

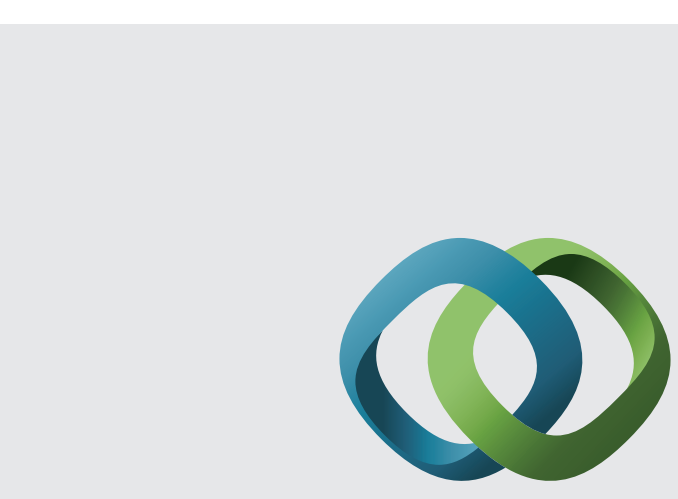

\section{Hindawi}

Submit your manuscripts at

http://www.hindawi.com
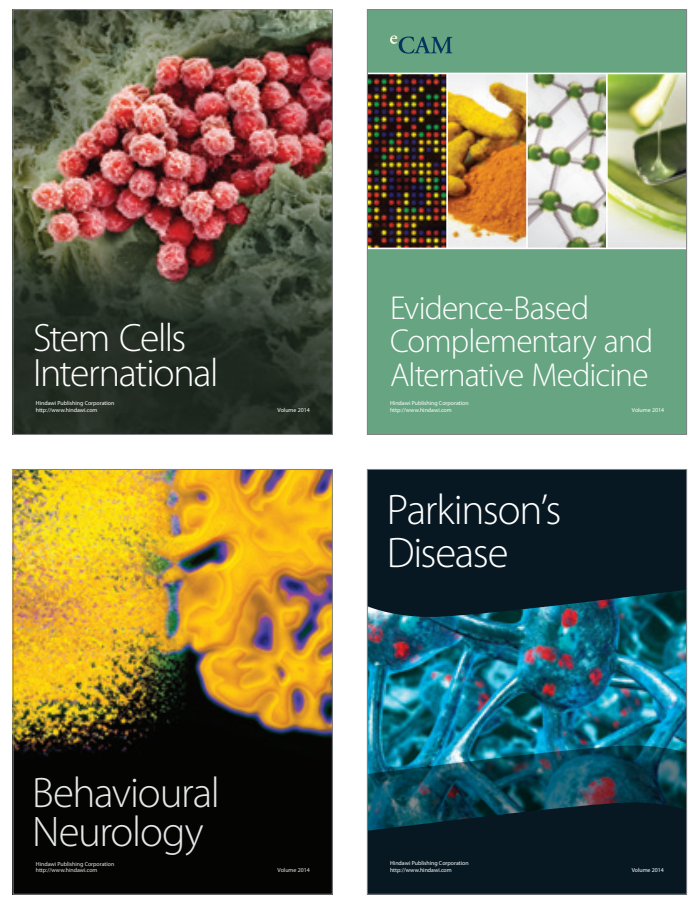
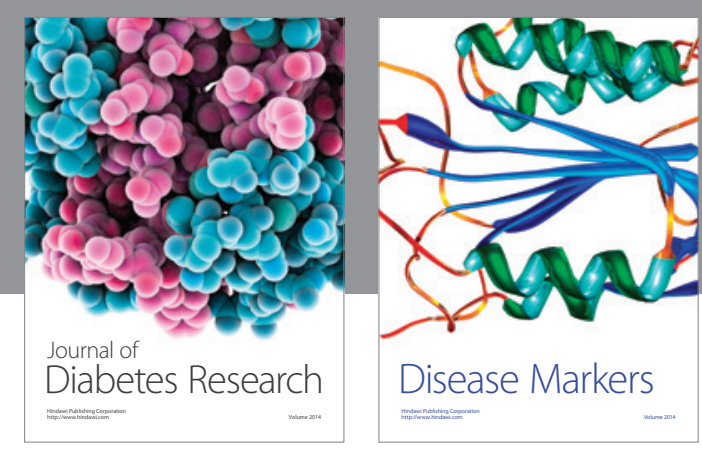

Disease Markers
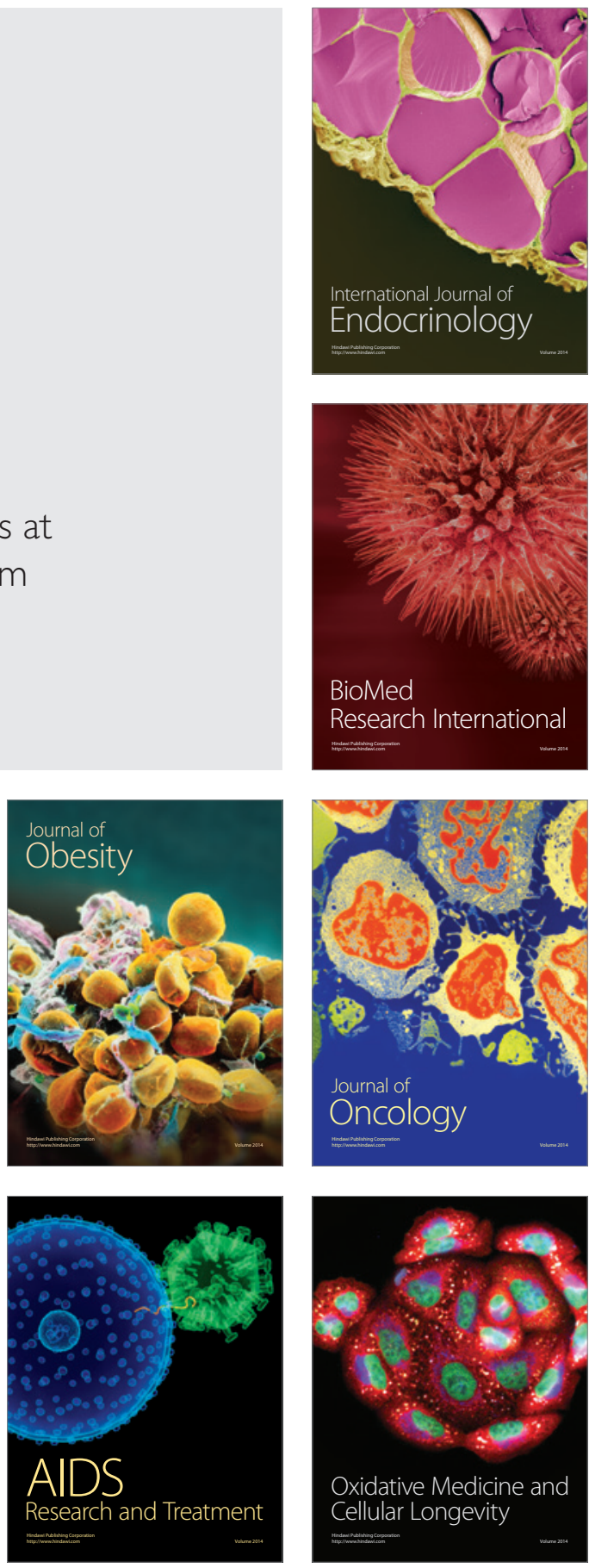